\title{
A Comperative Study on the Behavior of Cooling Towers Under Wind Loads Using Harmonic Solid Ring Finite Elements
}

\author{
Ali I.Karakas and Ayse T. Daloglu* \\ Civil Engineering Department, Karadeniz Technical University, Trabzon, 61080 Turkey. \\ Civil Engineering Department, Karadeniz Technical University, Trabzon, 61080 Turkey. \\ aliihsanka@yahoo.com, aysed@ktu.edu.tr
}

\begin{abstract}
The present work focuses on a comparative study for the responses of a cooling tower subjected to wind loadings described in accordance with Turkish Standard (TS 498) and Eurocode using harmonic solid ring finite elements. Nonaxisymmetric wind loadings around the circumfer ence make the cooling tower problem thre dimensional. However, using harmonic elements reduces the problem to a two dimensional problem by expressing the loading in the for $m$ of a Fourier series. Therefore, a finite element program is coded in Matlab incorporating harmonic finite element techniques. The wind analyses of the cooling tower are conducted using 9-noded har monic solid ring finite element modeling. The har monic finite element formulations in general terms are presented in the study. The vertical and circumfer ential distributions of the wind loading effective on the cooling tower according to both standards are compared. The circumferential distributions are expressed using Fourier cosine series and the coefficients indicate that while the wind loading mainly will cause undulating deformations according to Eurocode and beam like deformations according to Turkish Standard (TS 498). Moreover, it is realized that the circumferential distribution of wind pressure influenced the magnitude of displacements and stresses significantly as well as the region under tension along the circumference of the cooling tower.
\end{abstract}

Index Terms - Wind load, cooling tower, harmonic solid ring finite elements

\section{INTRODUCTION}

$\mathrm{C}$ ooling towers are the essential components of many thermal and nuclear power stations. The towers vary in size that can be up to 200 meters tall and 100 meters in diameter having a complex hyperbolic geometry with thin walls. They may be subjected to a variety of loading conditions such as dead, wind, earthquake, temperature and construction loads. However, the wind load is considered to be the most critical load in the absence of earthquake. The wind

load is dependent on the vertical and circumferential variation which is special to cylindrical type structures such as cooling towers. The circumferential distribution of the wind pressure is determined by the laboratory and field measurements and most of the codes or standards provide an analytical function to approximate the distribution. These distribution functions may change for various codes or standards valid in different countries of the world. These curves are too complex in most of them to be able to consider in the structural analysis of cooling towers. The desire of presenting the real wind distribution produces complex curves around the circumference of the cooling towers. These curves may be considered as symmetrical or unsymmetrical with respect to plane passing through the windward meridian of the tower. The complexities in geometry and wind load distribution have attracted the attention of many researchers throughout the world. Therefore, the response analyses of hyperbolic cooling towers subjected to wind loads have been performed by several researchers [1-4]. Viladkar et al. [5] worked on the numerical modeling of a hyperbolic cooling tower under symmetrical wind loading in accordance with Indian and British Standards using linear elastic brick finite elements. Similarly Noorzaei [6] investigated the behavior of cooling tower shell subjected to unsymmetrical wind loading described in American Standard using 20-noded solid isoparametric finite elements.

The present work focuses on a comparative study for the behavior of complex hyperboloid cooling tower subjected to symmetrical wind loadings obtained in accordance with Turkish Standard and Eurocode. The structural analyses are conducted using finite element method with harmonic solid ring elements. With the help of harmonic analysis physically three dimensional problems are reduced to two dimensional problems by expressing non-axisymmetric wind loading in the form of Fourier series. Then, the complete solution is obtained

by superimposing a reasonable number of solutions for the wind load. For this purpose a finite element program is coded in Matlab utilizing 9-noded (Ring9) solid quadrilateral ring elements. In the following sections the formulations of the harmonic ring finite element in general terms are presented and 
displacements and stresses at the windward meridian of the middle surface of the wall and around the circumference of the cooling tower subjected to wind loads described in accordance with Turkish Standard and Eurocode are compared and presented in graphical format.

\section{HARMONIC RING FINITE ELEMENT MODEL}

For harmonic model, it is possible to demonstrate that in a linear analysis when the loads are expanded in Fourier series the displacement components can also be described by Fourier series in terms of the circumferential coordinate $\theta$ as [7]:

$$
\{u(r, \theta, z)\}=\left\{\begin{array}{l}
u_{r} \\
u_{\theta} \\
u_{z}
\end{array}\right\}=\left\{\begin{array}{l}
\bar{u}_{r}+\overline{\bar{u}}_{r} \\
\bar{u}_{\theta}+\overline{\bar{u}}_{\theta} \\
\bar{u}_{z}+\overline{\bar{u}}_{z}
\end{array}\right\}=\left\{\begin{array}{l}
\sum_{m=0}^{\infty} \bar{u}_{r m} \cos m \theta+\sum_{m=0}^{\infty} \bar{u}_{r m} \sin m \theta \\
\sum_{m=0}^{\infty} \bar{u}_{\theta m} \sin m \theta-\sum_{m=0}^{\infty} \overline{\bar{u}}_{\theta m} \cos m \theta \\
\sum_{m=0}^{\infty} \bar{u}_{z m} \cos m \theta+\sum_{m=0}^{\infty} \bar{u}_{z m} \sin m \theta
\end{array}\right\}
$$

where $\mathrm{m}$ is the circumferential mode (harmonic) number and symbols $u_{r}, u_{\theta}$ and $u_{z}$ indicate the radial, circumferential and axial displacement components, respectively, see Fig. 1. All barred quantities in Eq. (1) are amplitudes approximated using the finite element method, which are functions of $r, z$ but not of $\theta$. This produces a harmonic finite element in the $(r, z)$ plane. Single and double barred amplitudes represent symmetric $(f(\theta)=f(-\theta)) \quad$ and anti-symmetric $(f(\theta)=-f(-\theta))$ displacement terms, respectively. The amplitudes of the displacement components in Eq. (1) can be interpolated from nodal amplitudes using the shape functions. Fig. 1 shows the shape and node numbering of the 9-noded ring element as well as coordinate system.

In this study the formulation of symmetric part of the harmonic ring finite element is presented for the simplicity and a detailed explanation and anti-symmetric formulation can be found in [8]. The vector of displacement field within the element can be described in the following form that subscript $i m$ specifies that amplitude refers to node $i$ and harmonic $\mathrm{m}$ [9].

$$
\{\bar{u}\}=\left\{\begin{array}{l}
\bar{u}_{r}(r, \theta, z) \\
\bar{u}_{\theta}(r, \theta, z) \\
\bar{u}_{z}(r, \theta, z)
\end{array}\right\}=\sum_{m=0}^{\infty}\left(\left[{\overline{g_{\theta m}}}_{]_{u}}[N]\left\{\bar{d}_{m}\right\}\right)\right.
$$

where $\{\bar{d}\}_{m}$ is the nodal displacement vector for the Fourier term (mode) $\mathrm{m}$ and $[N]$ is the shape functions matrix, which are defined for a biquadratic ring element (Ring9) used in the present study as written by,

$$
\{\bar{d}\}_{m}=\left[\begin{array}{lll}
\left\{\bar{u}_{1 m}\right\}^{T} & \left\{\bar{u}_{2 m}\right\}^{T} \quad \ldots & \left\{\bar{u}_{9 m}\right\}^{T}
\end{array}\right]^{T}
$$

where

$$
\left\{\bar{u}_{i m}\right\}=\left\{\begin{array}{l}
\bar{u}_{\text {rim }} \\
\bar{u}_{\theta i m} \\
\bar{u}_{\text {zim }}
\end{array}\right\}
$$$$
[N]=\left[\begin{array}{llll}
{[N]_{1}} & {[N]_{2}} & \ldots \ldots & {[N]_{9}}
\end{array}\right]
$$

where

$$
[N]_{i}=\left[\begin{array}{ccc}
N_{i} & 0 & 0 \\
0 & N_{i} & 0 \\
0 & 0 & N_{i}
\end{array}\right]
$$

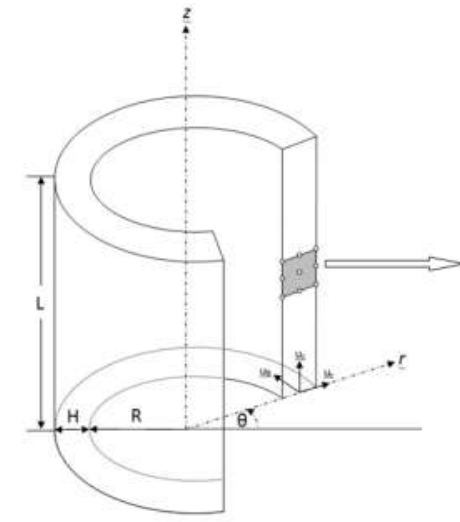

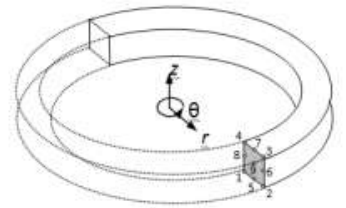

(b)
Fig 1. (a) Displacement components in cylindrical system (b) a solid ring finite element.

The shape function components at each node i for the 9-noded element in terms of natural coordinate system are expressed as [10].

$N_{i}=\frac{1}{4} \xi \eta\left[\left(\xi+\xi_{i}\right)\left(\eta+\eta_{i}\right) \quad\right.$ for $\mathrm{i}=1,2,3,4$

$N_{i}=\frac{1}{2} \eta\left(1-\xi_{i} \xi^{2}\right)\left(\eta+\eta_{i}\right) \quad$ for $\mathrm{i}=5,7$

$N_{i}=\frac{1}{2} \xi\left(\xi+\xi_{i}\right)\left(1-\eta_{i} \eta^{2}\right) \quad$ for $\mathrm{i}=6,8$

$N_{9}=\left(1-\xi^{2}\right)\left(1-\eta^{2}\right)$

where $\xi_{i}=(-1,1,1,-1,1,1,1,-1)$ and $\eta_{i}=(-1,-1,1,1,-1,1,1,1)$. Also, the matrices of harmonic functions for harmonic $m$ are 
$\left[\overline{g_{\theta m}}\right]_{u}=\left[\begin{array}{ccc}\cos m \theta & 0 & 0 \\ 0 & \sin m \theta & 0 \\ 0 & 0 & \cos m \theta\end{array}\right]$

Strains and stresses in an element can also be stated in terms of the Fourier series. For a Fourier term $\mathrm{m}$, the strain vector in cylindrical coordinates can be written as,

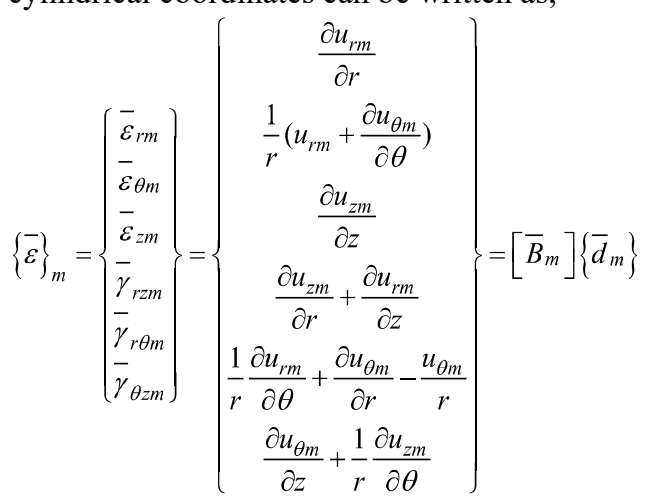

The strain displacement matrices can be stated as follows for harmonic $\mathrm{m}$ :

$[\bar{B}]_{m}=\left[\overline{g_{\theta m}}\right][B]_{m}=\left[\overline{g_{\theta m}}\right]\left[\begin{array}{l}{\left[B_{m}\right]_{\varepsilon}} \\ {\left[B_{m}\right]_{\gamma}}\end{array}\right]=\left[\overline{g_{\theta m}}\right]\left[\begin{array}{llll}{[B]_{11 m}} & {[B]_{12 m}} & \cdots & {[B]_{1 b m}} \\ {[B]_{21 m}} & {[B]_{22 m}} & \cdots & {[B]_{2 b m}}\end{array}\right]$

where $\left[\bar{B}_{m}\right]$ is the matrix which relates the symmetric nodal displacement amplitudes with corresponding strains and the matrix $\left[\overline{g_{\theta m}}\right]$ of the harmonic functions for the harmonic $\mathrm{m}$ is:

$$
\left[\overline{g_{\theta m}}\right]=\left[\begin{array}{cc}
{\left[\overline{g_{\theta m}}\right]_{\mathcal{E}}} & 0 \\
0 & {\left[\overline{g_{\theta m}}\right]_{\gamma}}
\end{array}\right]
$$

where

$$
\left[\overline{g_{\theta m}}\right]_{\varepsilon}=\cos m \theta\left[\begin{array}{ccc}
1 & 0 & 0 \\
0 & 1 & 0 \\
0 & 0 & 1
\end{array}\right]
$$

$[B]_{1 i m}=\left[\begin{array}{ccc}N_{i, r} & 0 & 0 \\ \frac{N_{i}}{r} & \frac{m N_{i}}{r} & 0 \\ 0 & 0 & N_{i, z}\end{array}\right]$

$$
[B]_{2 i m}=\left[\begin{array}{ccc}
N_{i, z} & 0 & N_{i, r} \\
-\frac{m N_{i}}{r} & \left(N_{i, r}-\frac{N_{i}}{r}\right) & 0 \\
0 & N_{j, z} & -\frac{m N_{i}}{r}
\end{array}\right]
$$

The stress vector for the $\mathrm{m}^{\text {th }}$ harmonic in the cylindrical coordinate system related to the strain vector through the constitutive equations is given for an isotropic material as follows [11]:

$$
\{\bar{\sigma}\}_{m}=[D]\{\bar{\varepsilon}\}_{m}
$$

in which [D] is the material property matrix for isotropic materials given by the following equation where $E$ is modulus of elasticity and $v$ is Poisson's ratio.

$[D]=\left[\begin{array}{cc}{\left[E_{\varepsilon}\right]} & 0 \\ 0 & {\left[E_{\gamma}\right]}\end{array}\right],\left[E_{\varepsilon}\right]=\frac{E}{(1+v)(1-2 v)}\left[\begin{array}{ccc}1-v & v & v \\ v & 1-v & v \\ v & v & 1-v\end{array}\right]$

and $\left[E_{\gamma}\right]=\frac{E}{2(1+v)}$

\section{FINITE ELEMENT MATRICES}

\section{A. The Element Stiffness Matrix}

The stiffness matrix of a linear system is calculated from the derivation of the strain energy of an axisymmetrical solid ring element [12]. The element strain energy is given as

$U_{e}=\frac{1}{2} \int\{\varepsilon\}^{T}\{\sigma\} d V=\frac{1}{2}\{d\}^{T}[k]\{d\}$

and

$\left[\overline{g_{\theta m}}\right]_{\gamma}=\left[\begin{array}{ccc}\cos m \theta & 0 & 0 \\ 0 & \sin m \theta & 0 \\ 0 & 0 & \sin m \theta\end{array}\right]$

and for the $\mathrm{i}^{\text {th }}$ node, the submatrices are given as:
Substituting Eqs. (7) and (13) into Eq. (15) for single barred terms the stiffness matrix for symmetric terms in Fourier series expansion is obtained as:

$\left[\bar{k}_{m}\right]=\iint\left[B_{m}\right]^{T}\left(\int_{0}^{2 \pi}\left[\begin{array}{cc}{\left[\overline{g_{\theta m}}\right]_{\varepsilon}^{T}\left[E_{\varepsilon}\right]\left[\overline{g_{\theta m}}\right]_{\varepsilon}} & 0 \\ 0 & {\left[\overline{g_{\theta m}}\right]_{\gamma}^{T}\left[E_{\gamma}\right]\left[\overline{g_{\theta m}}\right]_{\gamma}}\end{array}\right] d \theta\left[B_{m}\right] r d r d z\right.$ 
It can be observed that each term in the products of $\left[\overline{g_{\theta m}}\right]_{\varepsilon}^{T}\left[E_{\varepsilon}\right]\left[\overline{g_{\theta m}}\right]_{\varepsilon},\left[\overline{g_{\theta m}}\right]_{\gamma}^{T}\left[E_{\gamma}\right]\left[\overline{g_{\theta m}}\right]_{\gamma}$ will be a function of $(E, v)$ multiplied by either $\cos ^{2} m \theta$ or $\sin ^{2} m \theta$. Thus, integration over the circumferential direction $\theta$ can be carried out explicitly. The stiffness matrix of a quadrilateral ring element can be numerically integrated by Gauss quadrature rule being the most suitable method for finite element applications. By taking explicit integrations and using numerical integration the stiffness matrices for symmetric terms are calculated from the following expressions as used the study:

for $m=0$

$$
\left[\bar{k}_{0}\right]=2 \pi\left(\begin{array}{l}
\sum_{k=1}^{p} \sum_{l=1}^{p} w_{k} w_{l}\left[B_{0}\right]_{\varepsilon}^{T}\left(\xi_{k}, \eta_{l}\right)\left[\bar{E}_{\varepsilon o}\right]\left[B_{0}\right]_{\varepsilon}\left(\xi_{k}, \eta_{l}\right) r\left(\xi_{k}, \eta_{l}\right) J\left(\xi_{k}, \eta_{l}\right) \\
+\sum_{k=1}^{p} \sum_{l=1}^{p} w_{k} w_{l}\left[B_{0}\right]_{\gamma}^{T}\left(\xi_{k}, \eta_{l}\right)\left[\bar{E}_{\gamma 0}\right]\left[B_{0}\right]_{\gamma}\left(\xi_{k}, \eta_{l}\right) r\left(\xi_{k}, \eta_{l}\right) J\left(\xi_{k}, \eta_{l}\right)
\end{array}\right)
$$

for $m>0$

$$
\left[\overline{k_{m}}\right]=\pi\left(\begin{array}{l}
\sum_{k=1}^{p} \sum_{l=1}^{p} w_{k} w_{l}\left[B_{m}\right]_{\varepsilon}^{T}\left(\xi_{k}, \eta_{l}\right)\left[E_{\varepsilon}\right]\left[B_{m}\right]_{\varepsilon}\left(\xi_{k}, \eta_{l}\right) r\left(\xi_{k}, \eta_{l}\right) J\left(\xi_{k}, \eta_{l}\right) \\
+\sum_{k=1}^{p} \sum_{l=1}^{p} w_{k} w_{l}\left[B_{m}\right]_{\gamma}^{T}\left(\xi_{k}, \eta_{l}\right)\left[E_{\gamma}\right]\left[B_{m}\right]_{\gamma}\left(\xi_{k}, \eta_{l}\right) r\left(\xi_{k}, \eta_{l}\right) J\left(\xi_{k}, \eta_{l}\right)
\end{array}\right)
$$

where $\xi_{k}$ and $\eta_{l}$ are the Gauss points abscissae whereas $w_{k}$ and $w_{l}$ are the corresponding integration weights, with indices $\mathrm{k}$ and I running from 1 to the number of Gauss points used. Also $\left[B_{m}\right]_{\varepsilon}\left(\xi_{k}, \eta_{l}\right)$ and $\left[B_{m}\right]_{\gamma}\left(\xi_{k}, \eta_{l}\right)$ mean that these matrices are evaluated at the Gauss points; likewise for $r\left(\xi_{\mathrm{k}}, \eta_{\mathrm{l}}\right)$, the radius of the Gauss point and $J\left(\xi_{k}, \eta_{l}\right)$, the Jacobian determinant that maps the area element in global coordinates $(r, z)$ to area in the natural coordinates $(\xi, \eta)$. The number of Gauss points is taken as $p=3$ in the study for full integration.

\section{B. The Element Force Vectors}

The nodal loads to be applied to the structure can be expanded in Fourier series for the symmetric surface load components as:

$$
\{q\}=\left\{\begin{array}{l}
q_{r}(r, \theta, z) \\
q_{\theta}(r, \theta, z) \\
q_{z}(r, \theta, z)
\end{array}\right\}=\left\{\begin{array}{l}
\sum_{m=0}^{\infty}\left(\bar{q}_{s r m}(r, z) \cos m \theta\right) \\
\sum_{m=1}^{\infty}\left(\bar{q}_{s \theta m}(r, z) \sin m \theta\right) \\
\sum_{m=0}^{\infty}\left(\bar{q}_{s z m}(r, z) \cos m \theta\right)
\end{array}\right\}
$$

in which symbols $q_{r}, q_{\theta}$ and $q_{z}$ indicate the radial, hoop and axial load components, respectively. The consistent force vectors are calculated from the derivation of the external work done by the applied loads. And using p-point unidimensional Gauss numerical integration for the consistent surface force vector the following expressions are obtained in which $J_{\Gamma}$ is the associated arc length Jacobian.

$\left\{\bar{f}_{s 0}\right\}=2 \pi \sum_{k=1}^{p} w_{k}[N]_{s}^{T}\left(\xi_{k}\right)\left[\begin{array}{lll}1 & 0 & 0 \\ 0 & 0 & 0 \\ 0 & 0 & 1\end{array}\right]\left\{q_{s 0}\right\} r\left(\xi_{k}\right) J_{\Gamma}\left(\xi_{k}\right)$ for $\mathrm{m}=0$

$$
\left\{\bar{f}_{s m}\right\}=\pi \sum_{k=1}^{p} w_{k}[N]_{s}^{T}\left(\xi_{k}\right)\left\{\bar{q}_{s m}\right\} r\left(\xi_{k}\right) J_{\Gamma}\left(\xi_{k}\right) \text { for } \mathrm{m}>0
$$

Also, $[N]_{S}$ is the value of $[N]$ at locations of surface load vectors and $\left\{\bar{q}_{s m}\right\}$ is the surface load amplitude vector for the Fourier term $\mathrm{m}$.

\section{SOLUTION PROCEDURE}

The matrix equation for static problems is given by

$$
\left[\bar{K}_{m}\right]\left\{\bar{U}_{m}\right\}=\left\{\bar{F}_{m}\right\}
$$

where $\left[\bar{K}_{m}\right]$ is the system stiffness matrix, $\left\{\bar{U}_{m}\right\}$ is the system nodal displacement amplitude vector, and $\left\{\bar{F}_{m}\right\}$ is the system nodal force amplitude vector for symmetric harmonic mode $\mathrm{m}$ and single barred terms in Fourier series expansion. Solution of the equation is obtained by the Gauss elimination procedure.

\section{NUMERICAL EXAMPLE}

In the present study the responses of an existing hyperbolic cooling tower at Stanwell Power Station, located west of Rockhampton in Queensland (Australia) subjected to different quasi-static wind loadings are investigated comparatively using 
the developed finite element program utilizing 9-noded

harmonic solid ring elements.

\section{A. Geometry and Material Properties of Cooling Tower}

The equation of the curve of cooling tower in the form of a hyperboloid of revolution is obtained by Eq. (23) since the hyperbolic curve has double curvature meeting at the throat the characteristic dimension is evaluated for the upper and lower portions of the curve as $b=90.07 \mathrm{~m}$ and $b=74.69 \mathrm{~m}$, by substituting the base $\left(\mathrm{d}_{\mathrm{U}}, \mathrm{Z}_{\mathrm{U}}\right)$ and the top $\left(\mathrm{d}_{\mathrm{H}}, \mathrm{Z}_{\mathrm{H}}\right)$ coordinates in Eq. (24) and (25), respectively. $Z$ coordinate is measured from the throat level. All dimensions in the R-Z plane are specified in the middle surface of the shell wall.

$4 R^{2} / d_{T}^{2}-Z^{2} / b^{2}=1$

where $b$ is calculated as for upper curve

$b=d_{T} Z_{H} / \sqrt{\left(d_{H}^{2}-d_{\tau}^{2}\right)}$

and for lower curve.

$b=d_{\tau} Z_{U} / \sqrt{\left(d_{U}^{2}-d_{\tau}^{2}\right)}$

A constant shell-wall thickness of $240 \mathrm{~mm}$, and reinforced concrete with Poisson's ratio of 0.2 and elastic modulus of 39 $\mathrm{GPa}$ are considered in the finite element numerical model. The geometry of the hyperbolic cooling tower are depicted in Fig. 2 and the geometrical values are presented in Table 1.

Table 1. Geometric details of hyperbolic cooling tower

\begin{tabular}{lcc}
\hline Description & Symbol & Value (m) \\
\hline Height above throat level & $Z_{H}$ & 25.90 \\
Height below throat level & $Z_{U}$ & 95.60 \\
Top diameter & $d_{H}$ & 58.04 \\
Throat diameter & $d_{T}$ & 55.78 \\
Shell base diameter & $d_{U}$ & 90.60 \\
Wall thickness & $t$ & 0.24 \\
\hline
\end{tabular}

\section{B. Wind Loading}

Cooling towers may be subjected to a variety of loading conditions such as self-weight, wind load, earthquake load, temperature effects and construction loads. In the scope of this study only wind load according to different codes or standards are considered. Wind loading is extremely important in cooling tower design since the pressure on the shell wall is very sensitive to the vertical variation and the circumferential variation of the wind which is peculiar to cylindrical bodies. The vertical and circumferential variations of the wind loading considered in the wind analysis of the cooling tower are obtained in accordance with Turkish Standards (TS 498) and Eurocode (EN 1991-1-4:2005).

The external wind pressure acting at any point on the shell wall surface is computed as

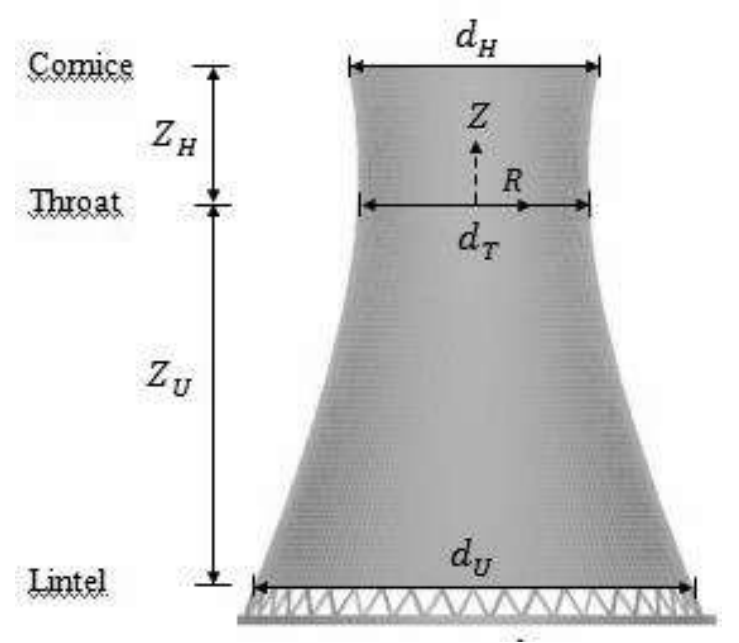

Fig 2. Geometry of the hyperbolic cooling tower

$$
q(z, \theta)=q(z) H(\theta)
$$

in which $q(z)$ is the effective velocity pressure at a height $z$ above the ground level and $H(\theta)$ is the coefficient for circumferential distribution of the external wind pressure. As mentioned $q(z)$ and $H(\theta)$ are obtained from codes in practice, TS 498 and Eurocode. Figs. 3(a,b) depict the vertical variations of effective velocity pressure, $q(z)$ in accordance with TS 498 and Eurocode, respectively. While the effective velocity pressure distribution throughout the height of the cooling tower varies uniformly in stepwise as shown in Fig. 3(a) according to TS 498 [13] the pressure distribution changes parabolically according to Eurocode as shown in Fig. 3(b). Additionally, the maximum effective velocity pressure is calculated as $2080 \mathrm{~N} / \mathrm{m} / \mathrm{m}$ according to TS 498 whereas it is $1634 \mathrm{~N} / \mathrm{m} / \mathrm{m}$ according to Eurocode at the top of the cooling tower for a basic wind velocity of $25 \mathrm{~m} / \mathrm{s}$.

The circumferential distribution of the wind pressure is denoted by $H(\theta)$ and is shown in Figs. 5 and 6 in accordance with TS 498 and Eurocode respectively for the half of cooling tower since it is symmetric with respect to plane passing through the key region, the windward meridian $\theta=0^{\circ}$. The wind pressure distribution coefficient over a circular section is sinusoidal in the first and fourth quadrant in TS 498 as depicted in Fig. 4(a) [14].

There is no suction over the circular section and compressive pressure is applied over the half of the section 
according to TS 498 as shown in Fig. 4(a) whereas in Eurocode the large portion of the load over the circular section is suction as shown in Fig. 4(b). It should be noted that the wind pressure distribution coefficients do not change with the height of the cooling tower for simplicity. For quantitative purposes, the equations of the pressure distribution curve called as K1.3 in Eurocode are given in Table 2.

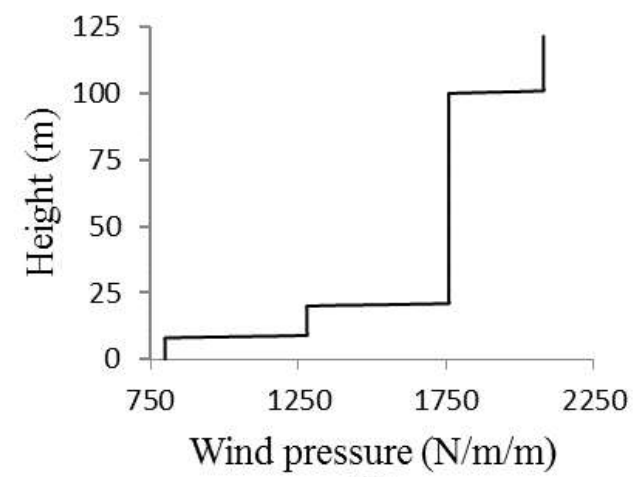

(a)

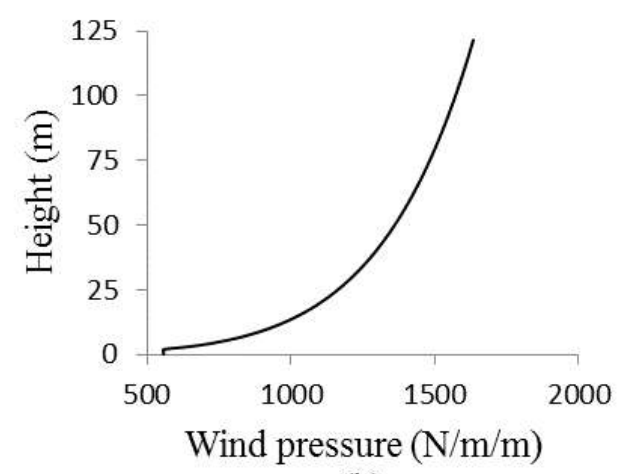

(b)

Fig 3. Wind pressure distribution with the height of the cooling tower a) TS 498 b) Eurocode

Table 2. Functions of pressure coefficient distribution curve in Eurocode [15]

\begin{tabular}{ll}
\hline Curve & $\mathrm{K} 1.3$ \\
Minimum pressure & -1.3 \\
$\theta \leq 73^{\circ}$ & $1-2.3\left(\sin \frac{90}{73} \theta\right)^{2.166}$ \\
$\theta \leq 93^{\circ}$ & $-1.3-0.8\left[\sin \left[\frac{90}{73}(\theta-73)\right]\right]^{2.395}$ \\
$\theta>93^{\circ}$ & -0.5
\end{tabular}

If the distribution $H(\theta)$ is represented in a Fourier cosine series of the form
$H(\theta)=\sum_{m=0}^{\infty} A_{m} \cos m \theta$

the Fourier coefficients $A_{m}$ for distributions most similar to curves shown in Figs. 4(a,b) are given in Table 3.

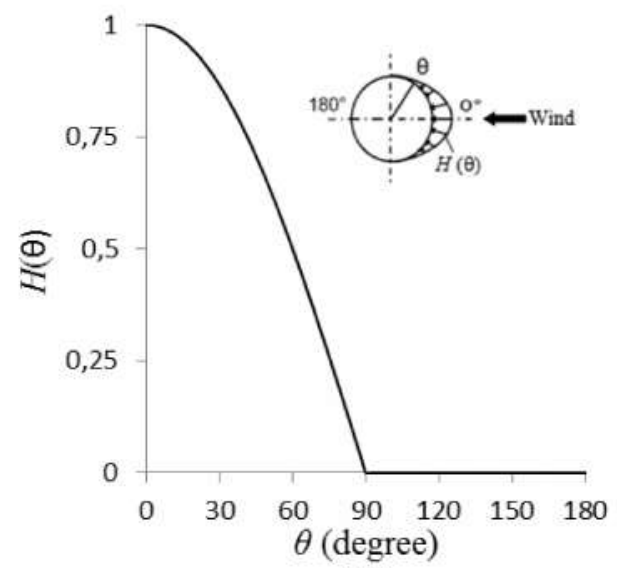

(a)

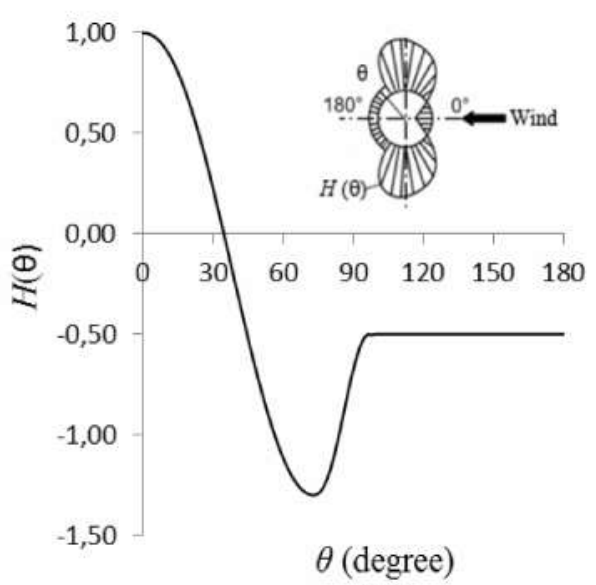

(b)

Fig 4. Circumferential wind pressure distribution coefficients a) TS 498 , b) Eurocode

Table 3. Fourier harmonic coefficients for the circumferential distribution of the wind load according to TS 498 and Eurocode

\begin{tabular}{|c|c|c|}
\hline \multirow[t]{2}{*}{$\mathrm{m}$} & TS 498 & Eurocode \\
\hline & \multicolumn{2}{|c|}{$A_{m}$} \\
\hline 0 & 0.3183 & -0.3922 \\
\hline 1 & 0.4937 & 0.2602 \\
\hline 2 & 0.2122 & 0.6024 \\
\hline 3 & 0 & 0.5046 \\
\hline 4 & -0.0424 & 0.1064 \\
\hline 5 & 0 & -0.0948 \\
\hline 6 & 0.0182 & -0.0186 \\
\hline 7 & 0 & 0.0468 \\
\hline
\end{tabular}


The distributions are approximated using eight harmonics with the coefficients in Table 3. Relatively large values for $m=2$ and $m=3$ in Eurocode indicate that a significant portion of the loading will cause shell deformations in these modes which produces local forces higher than a beam-like response forces. On the contrary, for TS 498 the largest coefficient is obtained for $m=1$ which is the translational mode causes beam-like response.

Fourier harmonics of the wind load distribution over the circumferential direction according to TS 498 and Eurocode are plotted in Figs. 5(a,b). Figs. 6(a,b) depict the combination of these eight harmonics or Fourier approximation and the actual wind load distributions. It can be concluded that good approximations are obtained using eight harmonics with the given coefficients in Table 3 for both TS 498 and Eurocode.

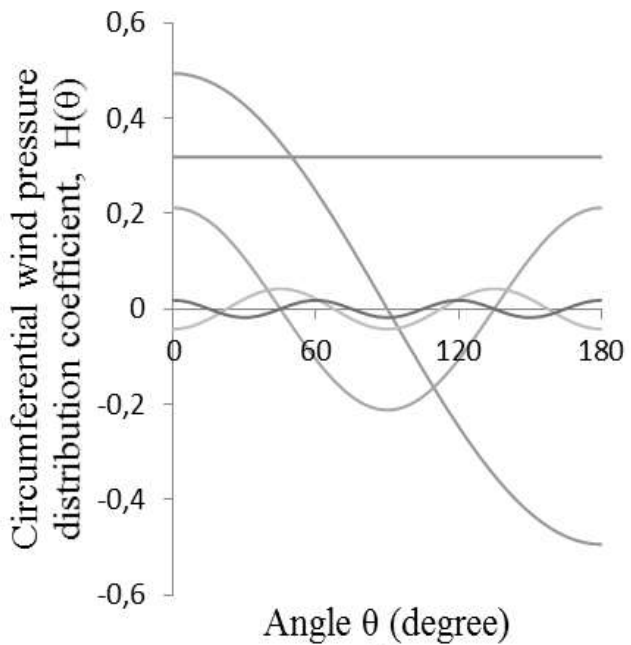

(a)

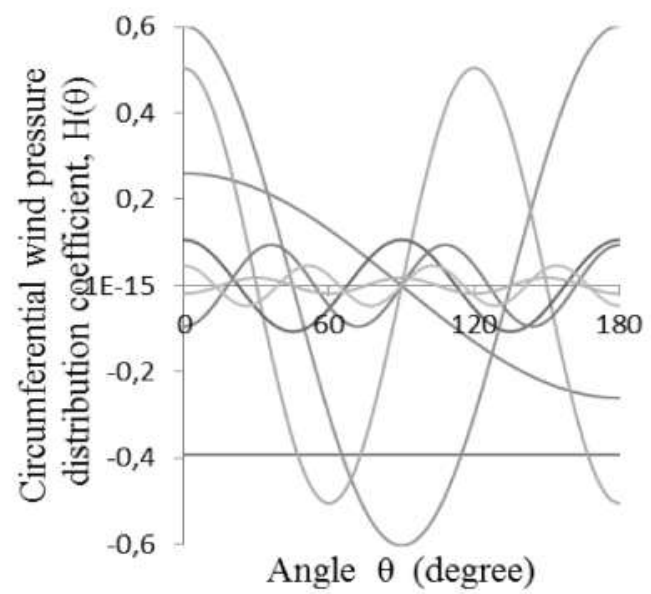

(b)

$$
\text { - } 0 \text { th }-1 \text { th }-2 \text { nd }-3 \text { rd }-4 \text { th }-5 \text { th }-6 \text { th }-7 \text { th hamonics }
$$

Fig 5. Fourier harmonics used to represent the wind load distribution coefficient over the circular section of the cooling tower a) TS 498 b) Eurocode

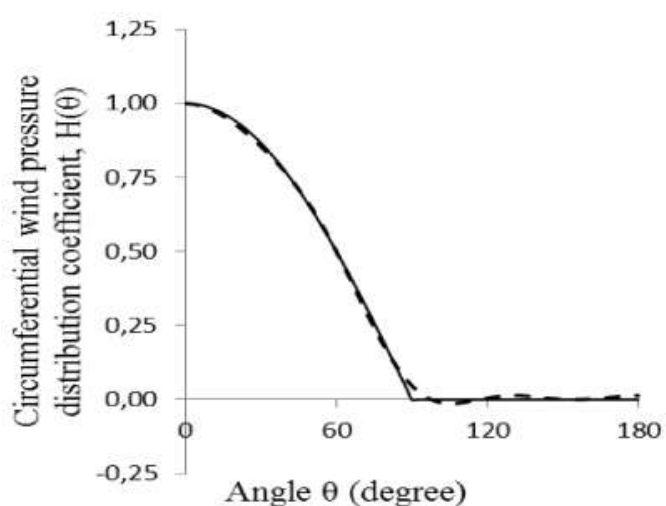

(a)

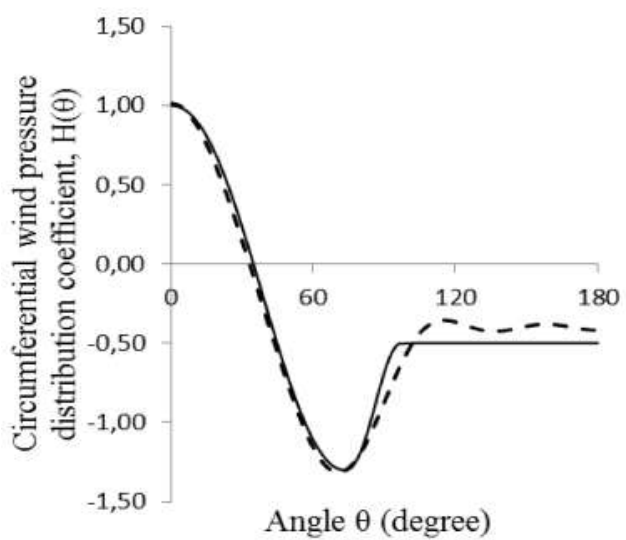

(b)

\section{- Real distribution -...- Fourier approximation}

Figure 6. Real distribution and Fourier approximation of the wind load distribution coefficients using eight Fourier harmonics for a) TS 498 b) Eurocode

\section{Static Analysis of the Cooling Tower}

The tower shell is considered to be fixed at the top of the columns in the finite element model. A convergence study is carried out and 100x2 Ring9 elements in axial and radial directions are decided to be sufficient for a good level of accuracy in the analysis. Figs. $7(\mathrm{a}, \mathrm{b})$ depict the radial displacements at the windward meridian $(\theta=0)$ of the cooling tower for each wind load harmonics according to TS 498 and Eurocode, respectively. The individual displacement responses of the cooling tower for each harmonic can be examined from these figures. 


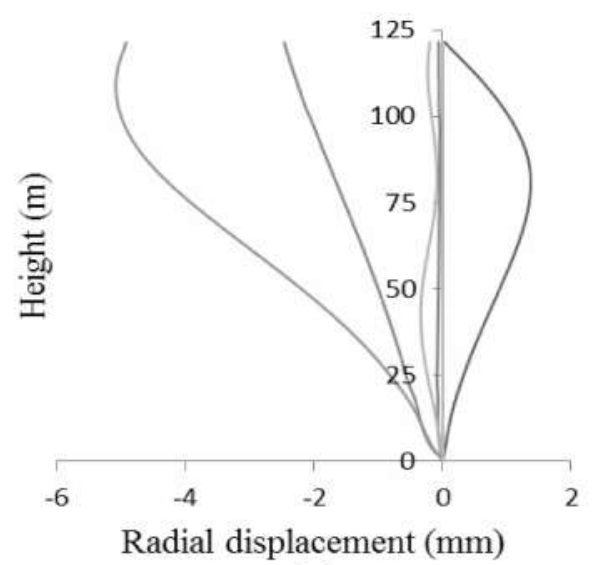

(a)

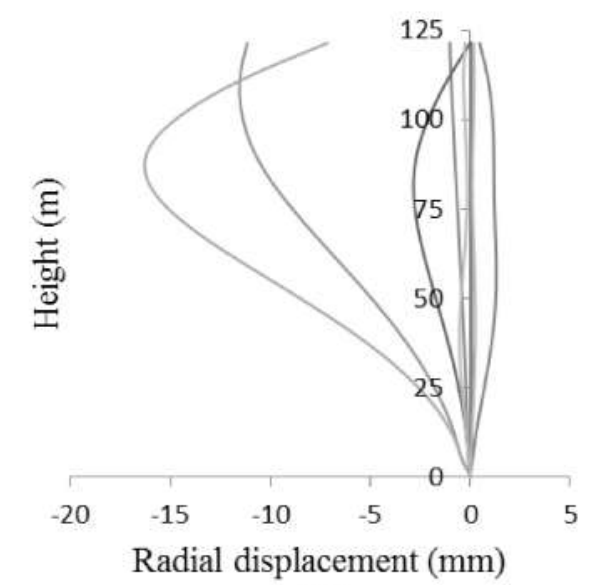

(b)

$$
\text { - Oth }-1 \text { th }-2 \text { nd }-3 \mathrm{rd}-4 \text { th }-5 \text { th }-6 \text { th }-7 \text { th hamonics }
$$

Fig 7. Radial displacements at windward meridian $(\theta=0)$ of the cooling tower along the height for each wind load harmonics a) TS 498 b) Eurocode

The cumulative wind load effect on the structure in terms of radial and axial displacements for both standards can be observed in Figs. 8(a,b). It can be recognized from Fig.8(a) that the maximum radial displacement along the height of the tower occurs at the cornice (top) with a value of $7.64 \mathrm{~mm}$ for TS 498 whereas the maximum radial displacement appears to be at the throat level $(\mathrm{H}=91.5 \mathrm{~m})$ with a value of $29.3 \mathrm{~mm}$ for Eurocode. The latter is about four times greater than the former due to the relatively large wind pressure distribution coefficients for circumferential modes $m>1$ in Eurocode. That is, these modes produce undulating deformations around the cross section. It should be noted that radial deflections are not just the beam-like deflections but the combination of both beam-like deformations and undulating deformations. When the Fig. 8(b) is considered it can be concluded that the axial displacements for TS 498 increase with the height since the tower behaves like a beam while for Eurocode the displacements oscillate through the height since higher modes $(m>1)$ lead to undulating shell deformations.

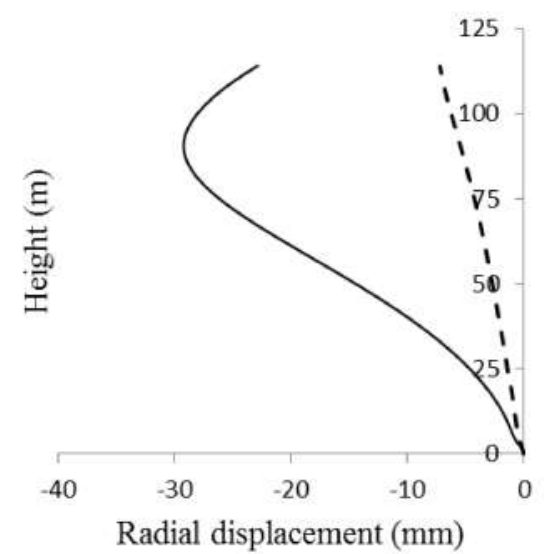

(a)

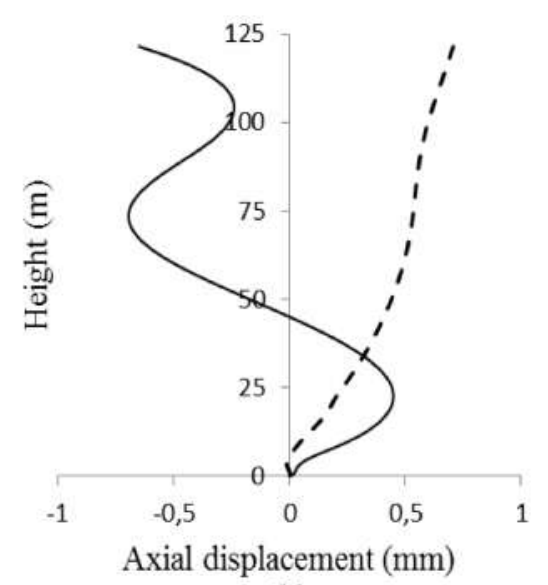

(b)

-..- TS 498 Eurocode

Fig 8. a) Radial b) Axial displacements at windward meridian $(\theta=0)$ of the cooling tower under wind load along the height accor ding to TS 498 and Eur ocode

The state of stress in the structure is the most critical information in a typical finite element analysis. Therefore, the distributions of meridional and circumferential stresses are investigated for both codes. In Fig $9(\mathrm{a}, \mathrm{b})$, meridional stress results of the analyses for each quasi-static wind load harmonics in accordance with TS 498 and Eurocode are depicted. The cumulative or complete responses of the cooling tower under wind loading are shown in Fig. 10(a,b). It can be seen from the figures that large tensions in both the meridional and circumferential directions are present. However, these values are significantly larger for Eurocode compare to the values for TS 498. For instance, the maximum circumferential tension stress at the bottom of the windward meridian is 192.6 
$\mathrm{kPa}$ for TS 498 whereas it is $529.8 \mathrm{kPa}$ for Eurocode. Moreover, the maximum meridional tension stress at the bottom of the windward meridian is $851.5 \mathrm{kPa}$ for TS 498 while the meridional stress appears to be maximum with a value of $2376.2 \mathrm{kPa}$ over a distance on the windward meridian from the bottom for Eurocode. Also, the region under tension extends a considerable distance along the circumference from the windward meridian at the cornice or lintel level and the magnitude is strongly dependent on the circumferential distribution as shown in Fig. 11(a,b).

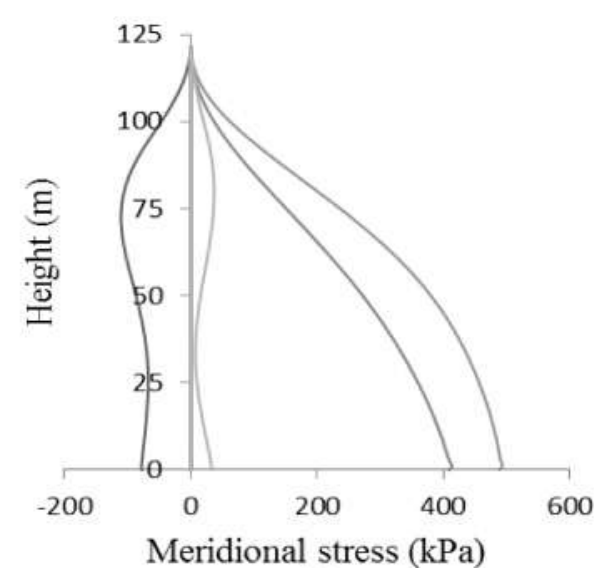

(b)

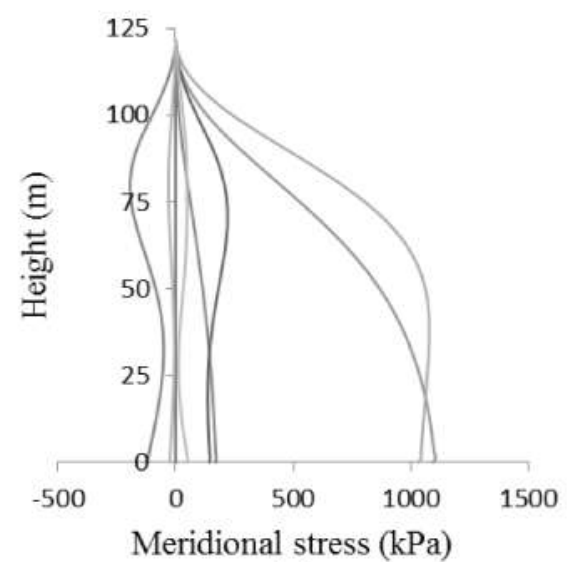

(a)

- 0 th -1 th -2 nd -3 rd -4 th -5 th -6 th -7 th harmonics

Fig 9. Meridional stresses at windward meridian $(\theta=0)$ along the height of the cooling tower for each wind load harmonics a) TS 498 b) Eurocode

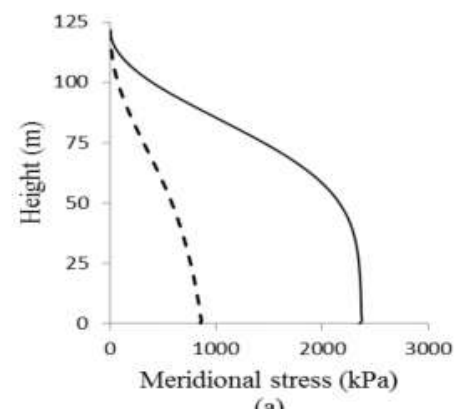

(a)

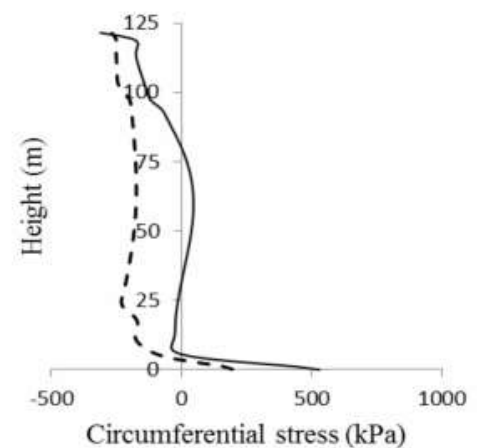

(b)

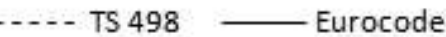

Fig 10. a) Meridional b) circumferential stresses at windward meridian $(\theta=0)$ throughout the height of the cooling tower under wind load according to TS 498 and Eurocode

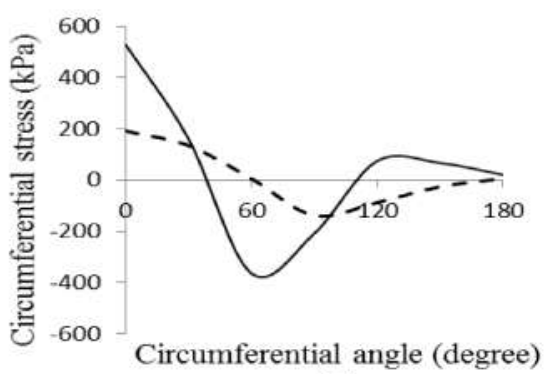

(a)

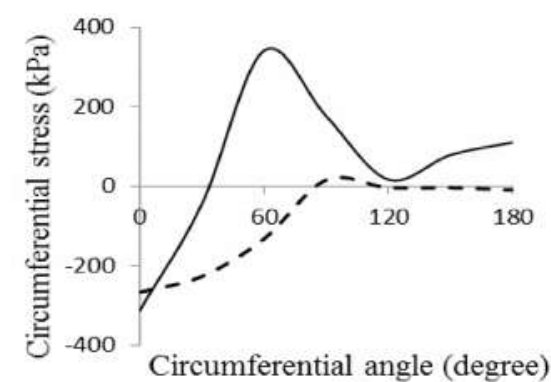

(b)

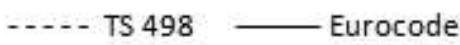

Fig 11. Distribution of the circumferential stresses around the circumference of the tower according to TS 498 and Eurocode at the a) lintel(base) b) cornice(top) level 


\section{CONCLUSIONS ACKNOWLEDGEMENTS}

A natural draught cooling tower which is one of the complex realistic axisymmetric structures subjected to nonaxisymmetric loadings such as wind pressure is analyzed statically using the coded Matlab finite element program incorporating 9-noded harmonic solid ring elements. The wind load pressures applied to the cooling tower are calculated in accordance with both Turkish Standard (TS 498) and Eurocode. In the present the analysis results such as the radial, axial displacements and circumferential, meridional stresses at the windward meridian $(\theta=0)$ of the middle surface of the cooling tower wall are compared for both TS 498 and Eurocode. Additionally, the distributions of meridional and circumferential stresses around the circumference at the lintel (base) and cornice (top) level of the tower are compared. The following conclusions can be drawn for the present study:

- Non-axisymmetric wind loadings can be expressed according to TS 498 and Eurocode using Fourier cosine series with eight harmonics.

- Fourier coefficients for Eurocode indicate that a great amount of the loading will cause shell deformations in circumferential mode greater than $m=1$ which is special to large cylindrical structures. However, TS 498 reflects that the tower deforms like a cantilever beam in which stresses along the height is a function of the overturning moment.

- Finally, the magnitude of tensile and compressive stress resultants and the region subjected to tension along the circumference are strongly dependent on the circumferential distribution of the applied wind pressure.

\section{REFERENCES}

[1] Prasahanth N and Sayeed Sulaiman, 2013, To study the effect of seismic loads and wind load on hyperbolic cooling tower of varying dimensions and rcc shell thickness, International Journal of Emerging Trends in engineering and Development, Vol:4-3, 260-269.

[2] G. Bosak and A. Flaga, Probabilistic and deterministic aspects of combinations of wind, thermal and dead loads on cooling towers, Journal of wind Engineering and Industrial Aerodynamics 65 (1996) $107-120$.

[3] Karisiddappa, M.N. Viladkar, P.N. Godbole, and P. Krishna, Finite element analysis of column supported hyperbolic cooling towers using semiloof Shell and beam elements, Engineering Structures 20 (1998) 75-85.

[4] G. Murali, C.M. Vivek Vardhan and B.V. Prasanth Kumar Reddy, Response of cooling towers to wind loads, ARPN Journal of Engineering and Applied Sciences, Vol:7-1, 2012,114-120.

[5] M.N. Viladkar, Karisiddappa, P. Bhargava, P.N. Godbole, Static soil structure interaction response of hyperbolic cooling towers to symmetrical wind loads, Engineering structures 28 (2006) 1236-1251.
[6] J. Noorzaei, A. Naghshineh, M.R. Abdul Kadir, W.A. Thanoon and M.S. Jaafar, Nonlinear interactive analysis of cooling tower-foundation-soil interaction under unsymmetrical wind load, Thin -Walled Structures 44 (2006) 997-1005.

[7] R.,D. Cook, D. S. Malkus, and M.,E. Plesha, Concepts and Applications of Finite Element Analysis, $3^{\text {rd }}$ Edition, Wiley \& Sons, USA, 1989.

[8] A. İ. Karakaș, Static and Dynamic Analyses of Axisymmetric Structures Using Harmonic Solid Ring Finite Element Modeling, Master dissertation. Karadeniz Technical University, Turkey, 2012.

[9] D. Benasciutti, F. De Bona, and M.Gh Munteanu,.Numerical analysistheory and application, In: Awrejcewicz J. editor, University of Udine, 2011.

[10] K.J. Bathe, Finite Element Procedures, Prentice-Hall, USA, 1996.

[11] M.A. Bhatti, Advanced Topics in Finite Element Analysis of Structures: with Mathematica and Matlab Computations, USA: John Wiley\&Sons, 2006.

[13] K..Halil, Spectral Analysis Program of Structures: SAPOS User Manual, Delft University of Technology, Netherlands, 79-90, 2009.

[14] TS 498, Yapı Elemanlarının boyutlandırılmasında alınacak yüklerin hesap değerleri, Türk Standartları Enstitüsü, 1997, Ankara.

[15] S. Bekiroğlu, p-Yöntemine dayalı üç boyutlu sonlu elemanlar ile yap1ları elastostatik ve dinamik analizi, Doktora Tezi, 2010, Karadeniz Teknik Üniversitesi, Fen Bilimleri Enstitüsü.

[16] prEn 1991-1-4, Eurocode 1: Actions on structures- Part 1-4: General Actions-Wind Actions, 2004, Brussels.

\section{ACKNOWLEDGEMENTS}

The first author has been supported by TUBITAK (Turkish Scientific and Technological Research Council) with a scholarship which is gratefully acknowledged. 